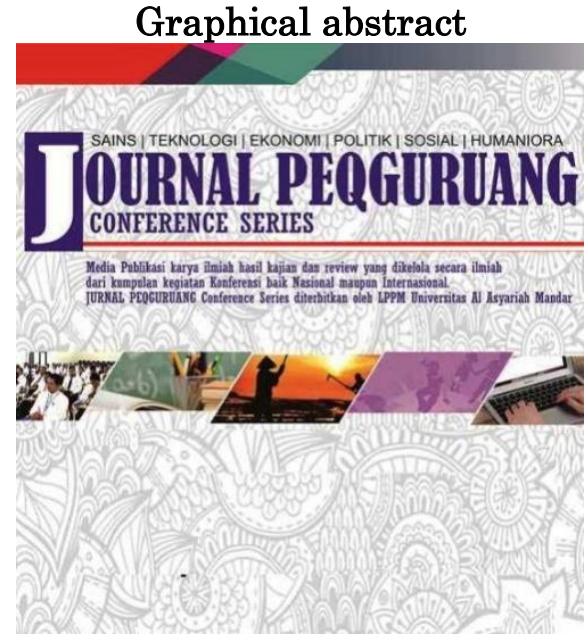

\title{
ANALISIS KUMPULAN PUISI JARAMMING KARYA SUPARMAN SOPU MENGGUNAKAN TEORI STRUKTURAL
}

${ }^{1 *}$ Rekapitayanti, ${ }^{*}$ Kamaruddin Tone, ${ }^{1 *}$ Abdul Muttalib.

*Universitas Al Asyariah Mandar rpitayanti@gmail.com

\section{ABSTRACK}

The purpose of this research is to describe Suparman Sopu's Poetry through structural theory. This research is a type of library research. Sources of data in this study are primary data and secondary data. Primary data that became the main data in the study are the opening prayer poetry, Owwa Owwa Owwaoo, Panjenengan, Lying in Parangtritis, Returning, Within Limits, 4-0 Score, Basa Basi Can, Percent, and Own Suparman Sopu's work and secondary data namely some literature that supports primary data. The method used to obtain data in this research is descriptive analysis methode that is readhing repetedly then analyzing and recording words, sentence expressions containing Structural Poetry which is the subject of thesis study. The cunclisions of the results of this study are: 1) Jaramming Extrinsic Structure by Suparman Sopu: a. Typography b. Diction c. Imagery d. Kongkret said e. Figurative Language (Majas) 2) Jaramming Intrinsic Structure by Suparman Sopu: a. Theme b. Tone c. Rasa d. Mandate. Data analysis Techniques used are: a. Data Reduction b. Data Model c. Whitdrawal/Verification Conclusion.

Keywords: Analysis, Poetry, Structural Theory.
Tujuan penelitian adalah untuk mendeskripsikan Puisi Karya Suparman Sopu melalui teori struktural Penelitian ini adalah data primer dan data sekunder. Data primer yang menjadi data pokok dalam penelitian yaitu puisi "Do'a pembuka, Owwa Owwa Owwaoo, Panjanengan, Berbaring di parangtritis, Kembali, Dalam Batas-Batas, Skor 4-0, Basa Basi Bisa, Persen, Sendiri” Karya Suparman Sopu dan data sekunder yaitu beberapa literatur yang mendukung data primer. Metode yang dipakai untuk mendapatkan data dalam penelitian ini adalah metode analisis deskriptif yaitu membaca berulang-ulang kemudian menganalisis dan mencatat kata, kalimat ungkapan yang mengandung Struktural Puisi yang menjadi bahan kajian skripsi. Simpulan hasil penelitian yaitu : 1) Struktur Ekstrinsik Jaramming karya Suparman Sopu: a. Tipografi b. Diksi c. Imaji d. Kata kongkret e. Bahasa figurative (Majas) 2) a. Tema b. Rasa c. Nada d. Amanat. Tekhnik Analisis Data yang digunakan yaitu: a. Reduksi Data b. Model Data c. Penarikan/verifikasi kesimpulan.

Kata Kunci: Anlisis, Puisi dan Teori Struktural

\section{Article history}

DOI: http://dx.doi.org/10.35329/jp.v2i2.1095

Received : 11 Agustus 2020 / Received in revised form : 3 September 2020 / Accepted : 15 oktober 2020

\section{PENDAHULUAN}

Sastra merupakan cerminan dan ekspresi kehidupan masyarakat.Banyak pengarang yang mengekspresikan dirinya melalaui karya satra, diantaranya berupa puisi.Puisi merupakan suatu karya yang terbentuk atas susunan kata penuh makna yang dibuat oleh penyair sebagai hasil penghayatan atau refleksi seseorang terhadap kehidupan melalui bahasa sebagai media pengungkapannya.Setiap karya sastra mempunyai unsur pembangun yang secara bersama-sama membentuk kesatuandaan susunan yang indah sehingga dapat dinikmati 
pembaca.Analisis struktural merupakan kajian kesusastraan yang menitikberatkan pada hubungan antar unsur pembangun sebuah karya sastra.Artinya, struktur karya sastra yang hadir dihadapan pembaca harus dipandang sebagai sebuah totalitasyang saling berhubungan.

Struktur ekstrinsik dan struktur intrinsik puisi ditelaah unsur-unsurnya. Kedua struktur itu harus mempunyai kepaduan dalam mendukung totalitas puisi.Telaah ini menyangkut telaah unsurunsur puisi dan berusaha membedah puisi sampai keunsur-unsur yang sekecil-kecilnya. Ditelaah bagaimana struktur ekstrinsik digunakan untuk mengungkapkan struktur intrinsik dan bagaimana struktur intrinsik dikemukakan. Telaaah yang demikian menghasilkan pembahasan puisi secara lebih mendalam.

Penelitian struktural biasanya mengkaji unsur ekstrinsik dan unsur intrinsik, dan dalam penelitian ini peneliti menggunakan unsur ekstrinsik dan unsur intrinsik.Dalam hal ini tidak ada bedanya dengan unsur batin dan unsur fisik, hanya saja jika menggunakan analisis ekstrinsik dan intrinsik biasanya pada kajian prosa sedangkan pada batin dan fisik untuk kajian puisi.

Penelitian mengenai unsur ekstrinsik dan intrinsik syair/puisi pernah diteliti antara lain : 1. Roselyn (2012) dengan judul "Analisis Perbandingan Struktur Batin dan Struktur Fisik Puisi "Lautan" Karya Rustam Effendi", penelitian ini membahas perbandingan struktur batin dan fisik puisi sedangkan penelitian yang peneliti dilakukan adalah analisis struktur ekstrinsik dan intrinsik pada puisi karya Suparman sopu. Penelitian yang juga berkaitan dengan penelitian mengenai kajian struktural antara lain "Kajian struktural dalam kumpulan puisi UPS karya Rieke Dia Pitaloka oleh Andi Suprianto Universitas Negeri Palembang (2002). Dalam simpulannya Andi mengemukakan bahwa dalam kumpulan puisi UPS karya Rieke Dia Pitaloka terdapat struktur fisik dan batin.

\section{Sastra}

Sastra adalah suatu karya tulis yang menggunakan bahasa indah dan memiliki keleluasan untuk berbeda dengan bahasa pada umumnya dan bahkan dapat melanggar aturan bahasa sehari-hari (Idrus, 2020:11

\section{Puisi}

Puisi adalah karya sastra yang khas penggunaan bahasanya dan memuat pengalaman yang disusun secara khas pula.Pengalaman intrinsik yang terkandung dalam puisi disusun dari peristiwa yang telah diberi makna dan ditafsirkan secara estetik (KBBI Edisi Ke-V).

\section{Teori Struktural}

Menurut Andriani (2016) Menjelaskan bahwa analisis struktural merupakan salah satu kajian kesusastraan yang menitikberatkan padaa hubungan antar unsur pembangun karya sastra. Struktur yang mebentukk karya sastra, khususnya puisi ialah struktur ekstrinsik dan struktur intrinsic. Struktur dihadapan pembaca merupakan sebuah totalitas. Puisi yang dibangun dari sejumlah unsur akan saling berhubungan sehingga menyebabkan puisi tersebut menjadi sebuah karya yang indah. Analisis struktural adalah analisis yang terbatas pada karya sastra itu sendiri.

\section{METODE PENELITIAN} Jenis Penelitian

Jenis penelitian yang digunakan dalam penelitian ini adalah jenis penelitian deskriptif kualitatif.

\section{HASIL DAN PEMBAHASAN}

a. Puisi 1: Do'a pembuka

1) Sruktur ekstrinsik pada puisi "Do'a pembuka"

a) Tipografi

Tipografi yang digunakan dalam puisi "Do'a pembuka" yaitu tipografi yang baris puisinya dimulai dengan huruf capital, jenis huruf kapitalnya yaitu capitalization.

b) Diksi 
Diksi yaitu pemilihan kata dengan memasukkan do'a pembuka dan penutup kedalam puisinya yang berbunyi:

'Assalamualaikumwarahmatullahi

wabarakatuh' dan baris ke tujuh 'Waalaikum salam warahmatullahi wabarakatuh'

c) Imaji

Penyair menggunakan imaji rasa agar puisinya terkesan lebih indah

d) Kata kongkret

Kata kongkret yang dipilih penyair diperlihatkan pada kata "kau sebut ha dalam kefasihan" yang melambangkan sesuatu yang bisa didengar karena berkaitan dengan ucapan.

e) Bahasa figuratif

Bahasa figuratif pada puisi "do'a pembuka" ini menggunakan majas hiperbola atau melebih-lebihkan.

2) Struktur intrinsik pada puisi "Do'a pembuka"

1) Tema

Pada puisi ini penyair memlilih tema yaitu panjatan do'a.

2) Rasa

Rasa pada puisi ini penyair memanjatkan do'a untuk seseorang yang jauh pandangan matanya, hal ini dapat dilihat dari penggalang puisi pada bait ke tiga baris ke tujuh yaitu:

Mendekat pada tempat RahmatNYA

3) Nada

Penyair menggunakan nada patriotic.

4) Amanat

Amanat yang ingin disampaikan oleh penyair dalam puisi ini menyadarkan pembaca agar senantiasa meminta petunjuk melalui do'a dalam melakukan segala hal. Itualah pembahasan puisi yang berjudul do'a pembuka.

\section{b. Puisi 2: Owwa Owwa Owwaooo}

1) Struktur ekstrinsik yang ada pada puisi "Owwa Owwa Owwaooo"

a) Tipografi

Tipografi pada puisi "owwa owwa owwa" menggunakan huruf kapital, jenis huruf kapitalnya yaitu capitalization.

b) Diksi
Diksi atau pemilihan kata dalam puisi ini dengan memasukkan bahasa Mandar kedalam puisinyayang berbunyi:

Kau dendangkan sayang-sayang-mu

Artinya: kau dendangkan sayang-sayang-mu (lagu yang dinyanyikan dengan iringan gitar Diayun di Toyang pelepah batang rumbia Artinya: Diayun di Toyang (ayunan) pelepah batang rumbia

c) Imaji

Penyair menggunakan imaji auditif atau sesuatu yang dapat didengar.

d) Kata Kongkret

Kata kongkret yang dipilih penyair dalam puisi ini diperlihatkan pada kata "kau dendangkan sayang-sayang-mu" yang melambangkan sesuatu yang berbunyi dan dapat didengarkan.

e) Bahasa Figuratif

Bahasa figuratif pada puisi owwa owwa owwaooo ini menggunakan majas penegasan.

2) Struktur Intrinsik yang terdapat dalam puisi "Owwa owwa owwaooo"

1) Tema

Pada puisi ini penyair memilih tema keberanian.

2) Rasa

Rasa pada puisi ini penyair mempunyai kebenarian.

3) Nada

Penyair menggunakan nada patriotic.

4) Amanat

Amanat yang disampaikan penyair pada puisi ini sangatlah banyak diantaranya dapat dilihat pada penggalang puisi di bait ke tiga baris ke delapan, sembilan dan sepuluh yang berbunyi:

cika ada rezeki yang engkau peroleh

Janganlah membuat dirimu boros

Sebab rezeki itu tidak selalu ada

c) Puisi 3: Puisi Panjenengan

1)Struktur Ekstrinsik yang ada pada puisi "Panjenengan"

1) Tipografi

Tipografi pada puisi ini diawal katanya menggunakan huruf kapital, jenis huruf kapitalnya yaitu capitalization. 
2) Diksi

Penyair memilih diksi dalam puisi ini dengan memasukkan bahasa Jawa dan bahasa Mandar kedalam puisinya, hal ini dapat dilihat pada judul puisi dan pada bait ke tiga baris kedua yaitu:

"Seperti paqjannangan" yang pernah dinyalakan nenekku

Artinya: seperti lampu minyak yang pernah dinyalakan nenekku

3) Imaji

Imaji yang digunakan penyair dalam puisi ini yaitu imaji auditif.

4) Kata Kongkret

Kata kongkret yang dipilih penyair dalam puisi ini dapat dilihat pada penggalang puisi bait pertama baris ke tujuh yang berbunyi:

"Senyum pagi menyejukkan"

Artinya: sapaan embun dipagi hari sangat terasa menyejukkan kalbu

5) Bahasa Figuratif

Bahasa figuratif yang digunakan penyair dalam puisi ini menggunakan majas perbandingan.

\section{2)Struktur Intrinsik pada puisi "Panjenengan"}

1) Tema

Pada puisi ini penyair memilih tema yaitu persamaan.

2) Rasa

Rasa pada puisi ini penyair merasakan persamaan.

3) Nada

Penyair menggunakan nada patriotik lum-sebelumnya

4) Amanat

Amanat yang dituliskan penyair dalam puisi ini mengingatkan pembaca untuk selalu menjadi manusia yang lebih baik lagi.

\section{d) Puisi 4: Puisi Berbaring di Parangtritis}

\section{1)Struktur Ekstrinsik pada puisi "Berbaring di Parangtritis"}

1) Tipografi

Tipografi yang digunakan penyair pada puisi ini penyusunan katanya diawali dengan huruf Kapital, jenis huruf kapitalnya yaitu capitalization.

2) Diksi

Dalam analisis diksi adalah pemilihan kata pada puisi ini diksi yang digunakan yaitu kata-kata yang umum namun tidak mengurangi keindahan pada puisi.

3) Imaji

Imaji pada puisi ini yang digunakan penyair yaitu imaji kinestik.

4) Kata Kongkret

Kata kongkret pada puisi ini yang dipilih penyair dapat dilihat pada penggalang puisi bait terakhir baris ke empat dan ke lima yang berbunyi:

Baris ke empat

"Kulihat Dato di Baurung Majene"

5) Bahasa Figuratif

Pada puisi ini bahasa figuratif atau majas yang digunakan penyair yaitu majas hiperbola.

\section{2) Struktur Intrinsik pada puisi "Berbaring di Parangtritis"}

1) Tema

Tema yang terdapat dalam puisi "Berbaring di Parangtritis" ini yaitu kesepian.

2) Rasa

Rasa pada puisi ini penyair merasakan kesepian ditengah keramaian.

3) Nada

Penyair menggunakan nada melankonik.

4) Amanat

Amanat yang ingin disampaikan penyair melalui puisi ini yaitu menyadarkan pembaca bahwasanya tidak selamanya orang dalam keramaian itu selalu bahagia.

e) Puisi 5: Puisi Kembali

1)Struktur Ekstrinsik yang ada pada puisi "Kembali"

1) Tipografi

Tipografi pada puisi ini penyair menggunakan huruf kapital diawal penyusunan katanya, jenis huruf kapitalnya yaitu capitalization. 
2) Diksi

Pilihan kata yang digunakan penyair dalam puisi ini tidak rumit dan mudah dipahami oleh pembaca karena panggunaan katanya sangat singkron.

3) Imaji

Imaji yang digunakan penyair dalam puisi ini yaitu imaji visual.

4) Kata Kongkret

Untuk kata kongkret yang digunakan penyair dalam puisi ini terdapat pada bait pertama baris pertama yang berbunyi:

"Kita harus kembali ke pantai dengan damai"

5) Bahasa Figuratif

Pada puisi ini bahasa figuratif atau majas yang digunakan penyair yaitu majas personifikasi.

2)Unsur Intrinsik yang ada pada puisi "Kembali"

1) Tema

Tema yang terdapat dalam puisi "Kembali" yaitu berdamai dengan kesendirian. 2) Rasa

Rasa pada puisi ini penyair merasakan semangat yang luar biasa dalam berlayar.Meskipun dia sendiri tetapi dia tidak pernah pantang mundur dalam melakukan segala hal.

3) Nada

Nada yang digunakan penyair dalam puisi yaitu nada patriotic.

4) Amanat

Amanat yang disampaikan penyair melalui puisi ini yaitu menyadarkan pembaca bahwa tidak selamanya sendiri itu harus sedih, kadang kala sendiri itu yang membuat seseorang merasa tenang dan damai.

\section{f) Puisi 6: Puisi Dalam Batas-Batas}

1)Struktur Ekstrinsik yang ada pada puisi "Dalam Batas-Batas"

1) Tipografi

Tipografi yang digunakan penyair dalam puisi ini yaitu diawal katanya semua menggunakan huruf kapital, jenis huruf capitalnya yaitu capitalization.

2) Diksi
Penyair memilih diksi dalam puisinya pada bait ke dua baris ke enam yang mengaitkannya dengan agama yaitu:

"Sungguh aku sangat kecil di jagatMU"

Artinya: Betapa kecil dirinya di bumi ini, semuanya mempunyai batas.

3) Imaji

Pada puisi ini imaji yang digunakan penyair yhaitu imaji kinestik.

4) Kata Kongkret

Kata kongkret yang dipilih penyair dalam puisi ini diperlihatkan pada bait ke dua baris ke tiga yang berbunyi:

"Dalam perjalanan di atas bis"

5) Bahasa Figuratif

Bahasa figuratif atau majas yang digunakan penyair dalam puisi ini yaitu majas penegasan.

\section{2)Struktur Intrinsik pada puisi "Dalam Batas" Batas"}

1) Tema

Tema yang terdapat dalam puisi ini yaitu keterbatasan.

2) Rasa

Rasa dalam puisi ini penyair berperan sebagai monolog.

3) Nada

Nada yang digunakan penyair dalam puisi ini yaitu nada penegasan.

4) Amanat

Amanat yang disampaikan penyair dalam puisi ini yaitu manusia mempunyai keterbatasan tidak semua hal bisa dia lakukan, untuk itu jika melakukan sesuatu janganlah tergesa-gesa karena selalu saja ada yang terlupa jika dilakukan dalam keadaan tergesa-gesa.

\section{g. Puisi 7: Puisi Skor 4-0}

1)Struktur Ekstrinsik pada puisi "Skor 4-0"

1) Tipografi

Tipografi yang digunakan penyair dalam puisi ini yaitu diawal katanya menggunakan huruf kapital, jenisnya huruf kapital yang digunakan yaitu capitalization.

2) Diksi 
Pemilihan kata yang digunakan penyair dalam puisi ini yaitu diksi yang mudah dimengerti.

3) Imaji

Untuk imaji pada puisi ini berupa imaji visual.

4) Kata Kongkret

Kata kongkret yang digunakan penyair dalam puisi ini dapat dilihat pada penggalang puisi di bait ke tiga baris ke tiga yang berbunyi:

"Ketika aku datang menyuarakan sebait kalimat dalam alunan manusia Balanipa"

Artinya: Datang dan seakan membangunkan orang-orang Balanipa dengan sebait kalimat yang dia suarakan.

5) Bahasa Figuratif

Bahasa figuratif atau majas yang digunakan penyair dalam puisi ini yaitu majas hiperbola atau melebih-lebihkan.

2)Struktur Intrinsik yang ada pada puisi "Skor 4-0"

1) Tema

Tema yang digunakan penyair dalam puisi ini yaitu prasangka.

2) Rasa

Rasa yang terdapat pada puisi ini yaitu prasangka.

3) Nada

Nada yang penyair gunakan pada puisi ini yaitu nada sinis (kurang senang).

4) Amanat

Amanat yang disampaikan penyair dalam puisi ini yaitu senantiasalah berprasangka baik dalam hal apapun, baik buruknya sesuatu itu tergantung dari prasangka kita.

\section{Puisi 8: Puisi Bisa Basa-Basi}

1)Struktur Ekstrinsik yang ada pada puisi "Bisa Basa-Basi"

1) Tipografi

Tipografi yang ada pada puisi ini yaitu semua awal katanya menggunakan huruf kapital, jenis huruf kapitalnya yaitu capitalization.

2) Diksi
Dalam diksi yang dipilih pada puisi ini penyair memilih diksi yang mudah dipahami pembaca.

3) Imaji

Imaji yang digunakan penyair dalam puisi ini yaitu imaji auditif.

4) Kata Kongkret

Kata kongkret yang penyair gunakan dalam puisi ini terdapat di bait ke dua baris ke tiga yang berbunyi:

"Memandang langit dan mengukirnya"

Artinya: Menatap langit dan mengukir apa yang dia pandang.

5) Bahasa Figuratif

Bahasa figuratif atau majas yang digunakan penyair dalam puisi ini yaitu majas penegasan.

2)Unsur Intrinsik pada puisi "Bisa Basa-Basi"

1) Tema

Tema yang digunakan penyair dalam puisi ini yaitu jangan basa-basi.

2) Rasa

Rasa pada puisi ini penyair merasakan penegasan.

3) Nada

Penyair menggunakan nada patriotic.

4) Amanat

Penyair menyampaikan amanat dalam puisi ini pada pembaca yaitu janganlah berbicara (basa-basi) hal-hal yang tidak berguna, karena hanya akan merugikan dirinya dan merugikan orang lain juga.

\section{Puisi 9: Puisi Persen}

1)Unsur Ekstrinsik yang ada pada puisi "Persen"

1) Tipografi

Tipografi pada puisi ini terdiri dari 21 baris dan diawal katanya menggunakan huruf kapital, jenis huruf kapitalnya yaitu capitalization.

2) Diksi

Pilihan kata yang penyair gunakan dalam puisi ini sama sekali tidak rumit juga tidak mengurangi keindahan puisi akan tetapi justru mendukung maksud puisinya.

3) Imaji 
Imaji yang digunakan penyair dalam puisi ini yaitu imaji visual (penglihatan).

4) Kata Kongkret

Kata kongkret yang ada pada puisi ini diperlihatkan pada bait pertama yang berbunyi:

"Kutangkap gelisah dari nadamu kawan

Kutangkap resah dari tutur yang engkau urai Kurasakan amarah dari nadimu"

5) Bahasa Figuratif

Bahasa figuratif atau majas yang penyair gunakan dalam puisi yaitu majas hiperbola.

\section{2)Unsur Intrinsik yang ada pada puisi "Persen"}

1) Tema

Tema yang penyair gunakan dalam puisi ini yaitu jangan lupakan perjuangan seseorang.

2) Rasa

Rasa dalam puisi ini penyair berperan sebagai monolog yaitu aku.

3) Nada

Nada yang digunakan penyair dalam puisi ini yaitu nada melankolik.

4) Amanat

Amanat yang disampaikan penyair melalui puisi ini yaitu menyadarkan pembaca jangan pernah melupakan perjuangan seseorang walaupun itu hanya hal-hal kecil yang dia lakukan untukmu.

\section{Puisi $10:$ Puisi Sendiri}

1)Unsur Ekstrinsik pada puisi "Sendiri"

1) Tipografi

Tipografi pada puisi ini terdiri dari dua bait empat belas baris dan penyusunan awal katanya menggunakan huruf kapital, jenis huruf kapitalnya yaitu capitalization.

2) Diksi

Dalam analisis, diksi adalah pilihan atau pemilihan kata yang biasanya diusahakan oleh penyair secermat mungkin.penyair menyeleksi kata-kata yang mudah dimengerti.

3) Imaji

Imaji yang digunakan penyair dalam puisi ini yaitu imaji gerak.
4) Kata Kongkret

Kata kongkret pada puisi ini diperlihatkan pada kata padatnya jalan yang berarti keramaian atau kebisingan.

5) Basa figuratif

Bahasa figuratif atau majas yang digunakan penyair dalam puisi ini yaitu majas penegasan tautology.

\section{2)Unsur Intrinsik yang ada pada puisi "Sendiri"}

1) Tema

Tema yang digunakan penyair dalam puisi ini yaitu sunyi ditengah keramaian.

2) Rasa

Rasa penyair untuk puisinya merasakan kesunyian ditengah-tengah keramaian yang dia tempati.

3) Nada

Penyair menggunakan nada melankolik karena menggambarkan suasana hati yang sedih.

4) Amanat

Amanat yang disampaikan penyair dalam puisi terakhirnya yaitu agar pembaca dalam mengarungi kehidupan jangan pernah melupakan apa yang pernah dilakukan orang lain terhadapmu, kecil atupun besar senantiasalah berbalas budi.

\section{SIMPULAN}

1. Struktur Ekstrinsik Jaramming karya Suparman Sopu:

Tipografi bentuk ekstrinsik atau penyusunan baris-baris dalam puisi. Peranan tipografi dalam puisi adalah untuk melahirkan aspek artistic visual dan untuk menciptakan nuansa makna tertentu. Selain itu tipografi juga berperan untuk menunjukkan adanya loncatan gagasan serta memperjelas adanya satuan-satuan makna tertentu yang ingin dikemukakan penyair.

Diksi yaitu pemilihan kata-kata yang dilakukan oleh penyair dalam puisinya karena puisi adalah bentuk dari karya sastra yang sedikit kata-katanya harus dipilih secermat mungkin.Pemilihan kata-kata dalam puisi erat kaitannya dengan makna keselarasan bunyi dan urutan kata. 
Imaji yaitu kata atau susunan kata yang dapat diungkapkan pengalaman indrawi seperti penglihatan, pendengaran, dan perasaan.

Kata kongkret yaitu kata yang dapat ditangkap dengan indra memungkinkan munculnya imaji.

Bahasa figurative atau majas yaitu bahasa yang berkhias yang dapat menghidupkan/meningkatkan efek dan menimbulkan konotasi tertentu.

2. Struktur Intrinsik Jaramming karya Suparman Sopu:

Tema merupakan gagasan pokok subjekmatter yang dikemukakan oleh penyair.Pokok pikiran atau pokok persoalan itu begitu kuat mendesak dalam jiwa penyair, sehingga menjadi landasan utama pengucapannya.

Nada dalam menulis puisi, penyair mempunyai sikap tertentu terhadap pembaca apakah dia ingin bersikap menggurui, menasehati, mengejek, menyindir, atau bersikap lugas hanya menceritakan sesuatu kepada pembaca ini disebut nada puisi.Nada dan suasana puisi saling berhubungan karena nada puisi menimbulkan suasana terhadap pembaca.

Rasa atau perasaan dalam menciptakan puisi, suasana perasaan penyair ikut mendeskripsikan dan harus dapat dihayati oleh pembaca. Untuk mengungkapkan tema yang sama, penyair yang sau dengan perasaan yang berbeda dari penyair lainnya sehingga hasil puisi yang diciptakan berbeda pula.

Amanat yang hendak disampaikan oleh penyair dapat ditelaan setelah kita memahami tema, rasa dan nada puisi itu.Tujuan amanat merupakan hal yang mendorong penyair untuk menciptakan puisinya.

\section{Daftar Pustaka}

Andiani, Andriani. "Peningkatan Kemampuan Menganalisis Unsur Intrinsik Cerpen dengan Model Inside Outside Circle
Siswa Kelas XI IPA 2 SMA Neg. 1 Polewali Kabupaten Polewali Mandar." Pepatudzu Media Pendidikan dan Sosial Kemasayarakatan 11.1 (2016): 19-32.

Idrus Agussalim, 2020. Analisis Citraan Dalam Novel "Natisha" Karya Khrisna Pabichara (Kajian Stilistika). Polewali Mandar : Universitas Al Asyariah Mandar

Roselyn Nainggolan, 2014. "Analisis Perbanidingan Struktur Batin dan Struktur Fisik Puisi "Lautan" Karya Rustam Efendi." Sumatra Utara: Pematangsiantar.

Aminuddin. 2003. Sekitar Masalah Sastra. Malang: Yayasan Asih Asah Asuh.

Aminuddin. 2004. Pengantar Apresiasi Karya Sastra. Bandung: Sinar Baru.

Baharuddin. 1999. "Kegiatan Apresiasi Sastra Siswa SMU Negeri 1 Kabupaten Barru: Suatu Tinjauan Deskriptif." Skripsi. Makassar: FBS, UNM.

Dick, Hartoko. 2005. Pengantar Ilmu Sastra. Jakarta: Gramedia.

Gulzar, Dhabit. 2012. Istilah-Istilah Dalam Drama. 